\section{Left main coronary artery ostial occlusion in a young man: late sequelae of Kawasaki's disease?}

\begin{abstract}
A 26-year-old man was admitted with a history of New York Heart Association (NYHA) class II dyspnoea of 2 months' duration. An electrocardiogram showed diffuse ST segment depression and ST segment elevation in aVR. Echocardiography showed anterior wall hypokinesia with moderate left ventricular dysfunction. Coronary angiography showed a normal right coronary artery (RCA) (figure 1A) and near total occlusion of the left main coronary artery ostium and collaterals filling the left main artery from the aortic sinus (figure 1B-D). The left system received heterocollaterals from the RCA. The entire aorta and branch vessels were normal. Vasculitis work up was negative. There was a history of hospitalisation at the age of 5 years with fever, oral desquamation, cervical lymphadenopathy, bilateral conjunctival discolouration and thrombocytosis according to the discharge summary. The aetiology pointed towards possible undiagnosed, untreated Kawasaki's disease (KD) during childhood or a rare congenital anomaly. The patient underwent successful coronary artery bypass surgery. In patients with persistent aneurysms, stenosis can develop years after the acute
\end{abstract}

episode of KD. ${ }^{1}$ It highlights the importance of follow-up and the need for serial angiograms in patients who develop coronary aneurysms, and to consider $\mathrm{KD}$ as an aetiology for ischaemic heart disease in the young.

\section{Suresh Madhavan, ${ }^{1}$ Gargi Sathish ${ }^{2}$}

${ }^{1}$ Department of Cardiology, Government Medical College, Kottayam, Kerala, India ${ }^{2}$ Department of Ophthalmology, Government Medical College, Kottayam, Kerala, India

Correspondence to Dr Suresh Madhavan, Department of Cardiology, Government Medical College, Kottayam, Kerala, India 686008; drsureshmadhavan76@gmail.com

Contributors SM diagnosed and treated the patient, made substantial contributions to the conception and design of the case report, and undertook the acquisition, analysis and interpretation of the data. GS assisted in drafting the article and revising it critically for important intellectual content.

Competing interests None.

Patient consent Obtained.

Provenance and peer review Not commissioned; externally peer reviewed.

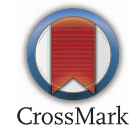

To cite Madhavan S, Sathish G. Heart Asia 2015;7:15. doi:10.1136/heartasia-2014-010598

Heart Asia 2015;7:15. doi:10.1136/heartasia-2014-010598

\section{REFERENCE}

1 Kato $\mathrm{H}$, Sugimura $\mathrm{T}$, Akagi $\mathrm{T}$, et al. Long term consequences of Kawasaki disease. A 10 to 21 year follow up study of 594 patients. Circulation 1996:94:1379-85.
Figure 1 (A) Right coronary angiogram showing a normal right coronary artery with collaterals to the left system. (B-D) Angiograms showing left main coronary artery (LMCA) ostial occlusion/severe stenosis with smoke-like collaterals from the aortic sinus filling the distal LMCA, left anterior descending artery, and the left circumflex artery.
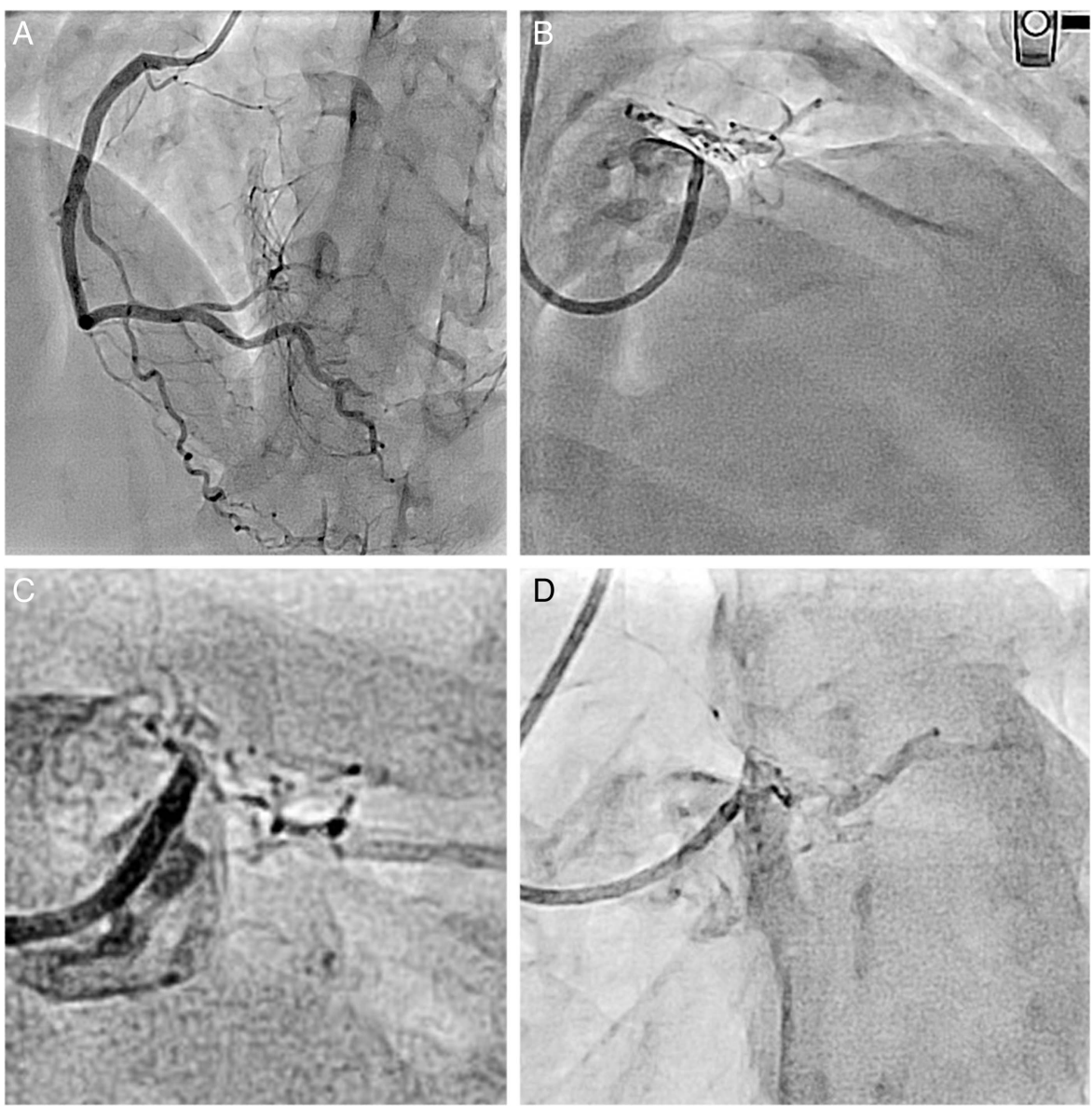